\title{
Adrenoceptor stimulation does not affect ICAM-1 and VCAM-1 expression in vitro
}

\author{
Heiner Ruschulte ${ }^{1 *}$, Dirk Scheinichen ${ }^{1}$, Martijn van Griensven², Susanne Weyrauch', Wibke Liefing ${ }^{1}$, \\ Birgitt Harrmeijer ${ }^{1}$, Michael Przemeck', Björn Jüttner ${ }^{1}$
}

\begin{abstract}
Background: Endothelial adhesion molecules ICAM-1 (CD54) and VCAM-1 (CD106) mediate cellular adhesion and transcellular migration. Cell adhesion and diapedesis have a key role in the course of shock and sepsis. During severe sepsis, adrenoceptor agonist levels may be increased due to endogenous production or due to intensive care treatment. As yet, the influence of $\beta 1$ or $\beta 2$ agonists on adhesion molecule formation on endothelial cells has remained unclear.
\end{abstract}

Methods: Cultured human umbilical vein endothelial cells were stimulated with E. coli. Following bacterial stimulation the cells were incubated with either $\beta 2$ receptor agonist terbutaline or $\beta 1$ agonist norepinephrine. ICAM-1 and VCAM-1 expression were examined using flow cytometry.

Results: Administration of norepinephrine did not cause increases of both CD54 and CD106 in stimulated HUVEC. Compared to negative controls the bacterial stimulation itself led to an increase of adhesion molecules. Following administration of terbutaline no significant increase in CD54 expression was found.

Conclusions: Bacterial stimulation led to an increase of adhesion molecule expression. Adrenoceptor stimulation of activated endothelial cells did not cause significant increases of cellular adhesion molecules.

\section{Background}

Endothelial cells are found in every vascularized tissue, and form the inner lining of the vascular and capillary wall. The main function of endothelial cells is to work as a communicative barrier between intravascular and extravascular spaces. Under physiologic conditions, there are regular intercellular and transcellular routes of transport of corpuscular and noncorpuscular agents from the luminal site to the abluminal site [1]. Contact and communication among cells either from identical or different types and sites depend on receptors and adhesion molecules anchored in the membrane of the cell.

Adhesion molecules are mediators between cells. During inflammation, ELAM-1 (E-selectin), intercellular adhesion molecule 1 (ICAM-1 (CD54)) and vascular adhesion molecule 1 (VCAM-1 (CD106)) are important for the interaction with peripheral blood cells. After bacterial invasion, cytokines like IL-1 $\beta$ or TNF-alpha, as

\footnotetext{
* Correspondence: ruschulte.heiner@mh-hannover.de

'Dept. of Anaesthesiology \& Intensive Care Medicine, Hannover Medical

School Hannover, Germany

Full list of author information is available at the end of the article
}

produced in tissue macrophages, cause E-selectin expression on endothelial surfaces. Following own selectin expression, white blood cells start rolling on endothelial surface which means deceleration and initiation of adherence. On the endothelial surface, ICAM-1 interacts with MAC-1 (= $\beta$-integrin) surface molecule of leukocytes. Contacts amongst endothelial cells and to monocytes or lymphocytes are mediated via endothelial VCAM-1 (CD106) and leukocytes surface molecule VLA-4. Upon activation, these adhesion molecules can be sledded from the cell surface and released into circulation [2].

During sepsis and multiple trauma physiological homeostasis mechanisms are disturbed. Patients frequently need pharmaceutical or mechanical organ function support. Hypodynamic or hyperdynamic circulatory dysregulation frequently require adrenoceptor agonist therapy. Under stimulation of $\beta 2$ adrenoceptors, reduced adherence of NK-cells [3], increased vasorelaxation [4], and reduced extravasation of fluids were observed. Besides treating the underlying condition, microvascular resuscitation is a crucial part of sepsis treatment [5]. 
It was our goal to investigate whether the expression of adhesion molecules is influenced by the use of norepinephrine or terbutaline, as this may be detrimental or beneficial during sepsis. We therefore examined the ex vivo effects of $\beta 1$ or $\beta 2$ stimulation on adhesion molecule expression in human endothelial cells by flow cytometry.

The questions especially addressed were: Is there an altered expression of adhesion molecules ICAM-1 or VCAM-1 by administration of a bacterial stimulus, or by the adrenoceptor agonist, or by both?

\section{Methods}

\section{Cell preparation and cell culture}

Cells were harvested using $0.04 \%$ collagenase (in PBS/ $\mathrm{MgCl}_{2}$ solution) from human umbilical cords. After centrifugation the cell pellets were put into $5 \mathrm{ml}$ medium (Endothelmedium, PromoCell, Heidelberg, Germany), given into culture flasks and incubated at $37^{\circ} \mathrm{C}$ and $5 \%$ $\mathrm{CO}_{2}$ (Incubator: Queue, Nunc, Wiesbaden, Germany). Cells were trypsinized and re-seeded at roughly $90 \%$ confluence. After the second or third passage, cells were used for stimulation and investigation of both $\beta 1$ agonist and $\beta 2$ agonist effects.

\section{Experimental setting}

Cells were stimulated overnight for 16 to 20 hours in the incubator $\left(37^{\circ} \mathrm{C}, 5 \% \mathrm{CO}_{2}\right)$ by adding E. coli $\left(3 \times 10^{7}\right.$ $\left.\times \mathrm{ml}^{-1}\right)(\mathrm{H} \mathrm{101}$, grown in Hannover Medical School's own laboratory).

After washing the cells with Ly-PBS (Hannover Medical School), $50 \mu$ l trypsin EDTA (Biochrom, Berlin, Germany) were given for detachment of the cells. Then, the cells were washed twice. Finally, $5 \mu \mathrm{l}$ of norepinephrine (Sigma Aldrich, Taufkirchen, Germany) or $10 \mu \mathrm{l}$ terbutaline (Sigma Aldrich, Taufkirchen, Germany) in $500 \mu \mathrm{l}$ Ly-PBS buffer were administered both at concentrations of $10^{-7} \mathrm{M}$ at a $\mathrm{pH}$ of 7.4. After 20 minutes' the incubations were stopped. $10 \mu \mathrm{l}$ of each antibody (ICAM-1, i.e. CD54, Beckman Coulter, Krefeld, Germany; VCAM-1, i. e. CD106 Serotec, Düsseldorf, Germany) both marked with the green fluorescent fluorescein isothiocyanate (FITC) were added. $20 \mu \mathrm{l}$ of the red fluorescent propidium iodide (PI; Sigma Aldrich, Taufkirchen, Germany) to stain DNA of dead cells, which should be excluded from our calculation, were also added. After 30 minutes of incubation (room temperature, dark) each tube again was centrifuged $\left(4^{\circ} \mathrm{C}, 2000 \mathrm{rpm}, 5 \mathrm{~min}\right)$ and the supernatant decanted to remove eventual detached adhesion molecules and antibodies. Cells were resuspended in $750 \mu \mathrm{l}$ binding buffer solution, put into FACS tubes (Sarstedt, Nürnberg, Germany) on ice and then analysed flowcytometrically (EPICS XL, Beckman Coulter, Krefeld, Germany).

\section{FACS analysis}

10,000 events per assay were measured after PI positive, i.e. dead, cells had been excluded. Events were depicted in dot plot diagrams to analyse the number of all events as a qualitative parameter. A life gate was then drawn around the HUVEC population. In a histogram the mean fluorescence of events as a quantitative parameter to analyse the distribution of a marked characteristic was registered.

\section{Data collection and statistical analysis}

All measurements were collected in an Excel (Microsoft) database and analysed with SPSS (11.0), p $<0.05$ was considered significant. All numeric data showed a Gaussian distribution (Kolmogorov-Smirnov-Test), so the univariate analysis of variance (ANOVA) (Fischer's exact test) was used to compare various concentrations of either $\beta 1$ or $\beta 2$ agonistic substances. Because not all the measurement showed skewness $|\gamma| \leq 0.4$, differences in adhesion molecule expression were compared in a paired Wilcoxon test. Correlation of quality (percent stimulation) and quantity (mean fluorescence) was calculated with correlation coefficient (Pearson).

Results are presented as mean and standard error of mean (mean \pm SEM percentage). Results were depicted as histograms reproducing the mean fluorescence which means quantitative adhesion molecule expression. We also calculated the relationships of norepinephrine administration compared to the baseline values which were depicted as box plots.

\section{Results}

HUVEC were investigated if there was a change in expression of the cellular adhesion molecules ICAM-1 and VCAM- 1 caused by either the $\beta 1$-stimulating agent norepinephrine or the $\beta 2$-agonist terbutaline with and without bacterial stimulation with $E$. coli.

Compared to negative controls (ICAM-1: $2.74 \pm 0.18$; VCAM-1: $3.76 \pm 0.13$ ), bacterial stimulation of HUVEC and additional norepinephrine administration caused a significant increase in ICAM-1 expression up to $20.64 \pm$ 2.88 and also a significant increase in VCAM-1 expression up to $5.73 \pm 0.41$ (Figures $1 \& 2$ ). Norepinephrine administration without bacterial stimulation did not cause relevant increases in adhesion molecule expression (ICAM-1: $2.76 \pm 0.67$; VCAM-1: $3.72 \pm 0.18$ ). Norepinephrine administration onto the stimulated cells caused significant effects in ICAM-1 expressions compared to negative controls, but roughly remained at levels as caused by bacterial stimulation only (ICAM-1: $19.81 \pm$ 2.53; VCAM-1: $5.30 \pm 0.37$ ). Administration of terbutaline (Figures 3 \&4) did not cause increases in both adhesion molecules investigated (negative controls $4.07 \pm$ 0.46 in ICAM-1, and $4.42 \pm 0.59$ in VCAM-1, 


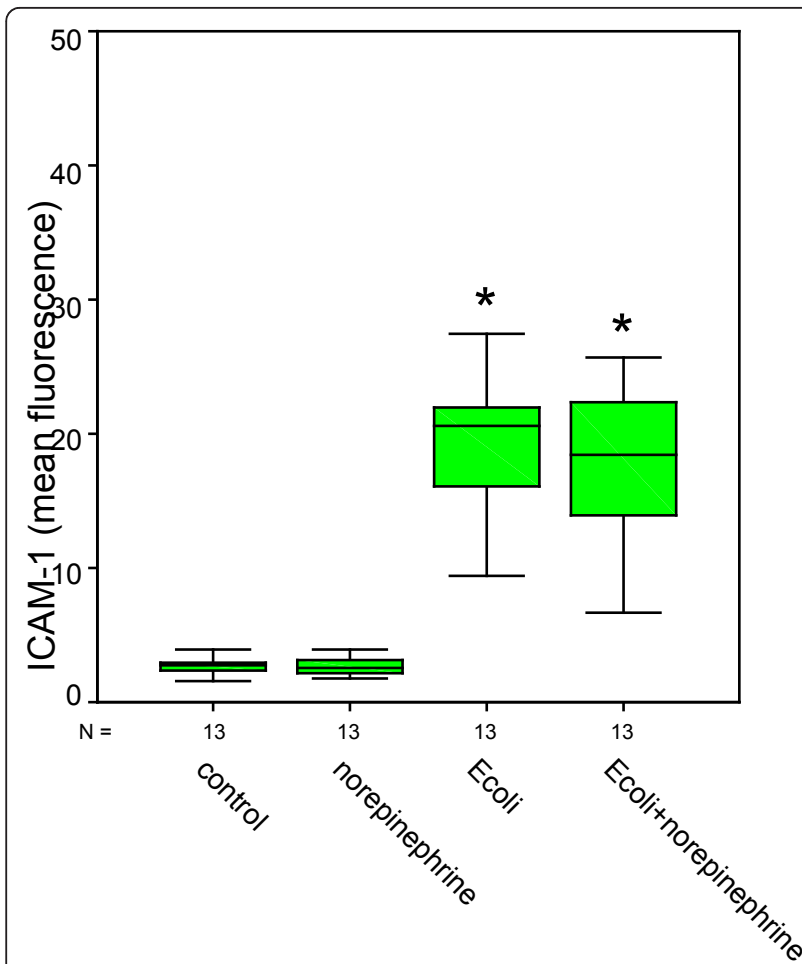

Figure 1 Quantitative changes in CD 54 (ICAM-1) expression following norepinephrine ( $\beta 1$ ) and bacterial (E. coli) stimulation. * statistical analysis $p=0.001$, versus negative control and versus $\beta 1$ stimulation, Wilcoxon test. (The box represents the mid 50\% range of the data. Whiskers are the lines that extend outwards from the ends of the box to a distance of at most 1.5 units of interquartile range.)

terbutaline administration $4.63 \pm 0.73$ in ICAM-1, and $4.80 \pm 0.71$ in VCAM-1, respectively). Mere bacterial challenge led to significant increases of both adhesion molecules' expressions compared to negative controls $(11.72 \pm 2.09$ in ICAM-1, and $8.78 \pm 0.95$ in VCAM- 1$)$ and compared to $\beta 2$ stimulation. These increases were even stronger under the combined administration of terbutaline and E. coli, the results were significant as compared to controls and to the $\beta 2$ stimulation (30.91 \pm 11.93 in ICAM-1, and $9.33 \pm 1.13$ in VCAM-1), but not when compared to bacterial stimulation.

\section{Discussion}

Endothelial cells can attract and bind immunocompetent cells, and are involved in host defence. Stimuli like bacteria or ischemia can also induce an exaggerated expression and release of adhesion molecules [6,7] leading to a loss of shape and function of the endothelial cell layer, capillary leakage and development of interstitial oedema which may be either a cause or a consequence of microcirculation disorders. Clinical presentation of the systemic inflammatory response syndrome (SIRS) includes tachycardia, hypotension,

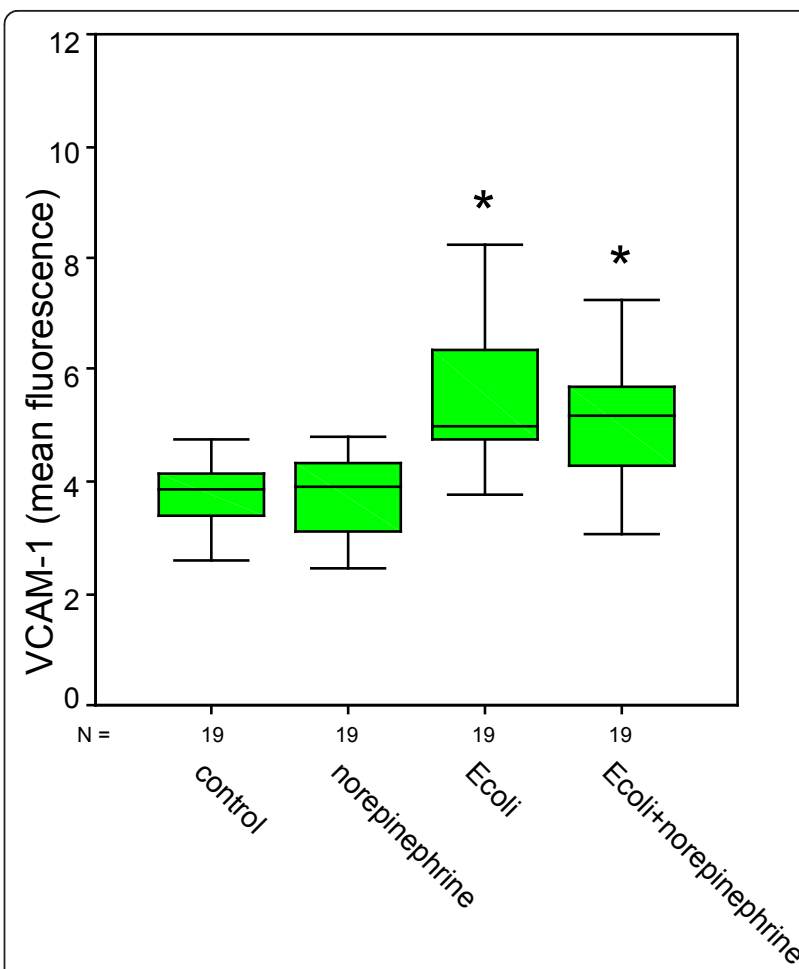

Figure 2 Quantitative changes in CD 106 (VCAM-1) expression following norepinephrine $(\beta 1)$ and bacterial (E.coli) stimulation. *statistical analysis $p \leq 0.001$, versus negative control and versus $\beta 1$ stimulation, Wilcoxon test. (The box represents the mid $50 \%$ range of the data. Whiskers are the lines that extend outwards from the ends of the box to a distance of at most 1.5 units of interquartile range.)

fever, and respiratory insufficiency. Intensive care therapy is required in these patients to restore and maintain tissue perfusion and oxygenation. Treatment often remains limited to symptomatic therapy as the focus or other causes of this overwhelming reaction cannot definitely be found in many cases. Treatment includes volume replacement and vasopressor therapy for circulatory and microvascular resuscitation [5]. Glucocorticoids are often administered to reduce inflammatory activity, but have not been shown to reduce levels of soluble adhesion molecules in septic patients [8]. Adrenoceptor agonist drugs are almost regularly administered in the treatment of septic patients during intensive care therapy. Norepinephrine is given to maintain circulation in terms of increasing vascular resistance and organ perfusion. In case a patient suffers from bronchial obstruction, $\beta 2$ agonists such as terbutaline can be given to improve ventilation.

Terbutaline as well as norepinephrine influence the properties of activated endothelial cells in vitro and in vivo: While norepinephrine led to an increase of interleukin-6 synthesis in LPS activated endothelial cells that was mediated by $\beta 1$-receptors [9], terbutaline 


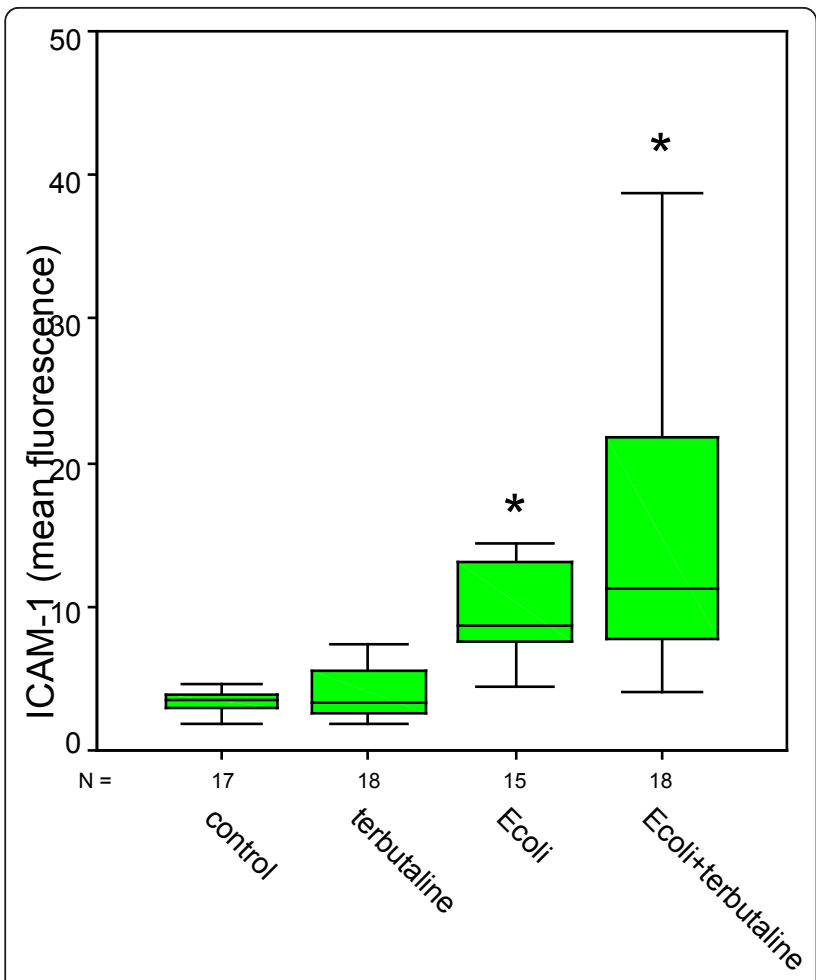

Figure 3 Quantitative changes in CD 54 (ICAM-1) expression following terbutaline $(\beta 2)$ and bacterial (E.coli) stimulation.

*statistical analysis $p \leq 0.001$, versus negative control and versus $\beta 2$ stimulation, Wilcoxon test. (The box represents the mid 50\% range of the data. Whiskers are the lines that extend outwards from the ends of the box to a distance of at most 1.5 units of interquartile range.)

application affected cell adhesion in rats in terms of an enhanced leukocyte rolling on endothelial cells [10].

Endothelial adhesion molecules are crucial in mediating innate and acquired immunity. During general systemic inflammation, Law et al. [11] described a connection between multiple organ failure and increased levels of soluble ICAM-1 in peripheral blood of patients following multiple trauma in a group of 13 individuals. Sessler [12] also found increased levels of circulating ICAM-1 levels in patients with septic shock. Furthermore, ICAM-1 deficient mice were less prone to septic shock than mice without any genetic manipulation [13-15] which indicates the important role of ICAM-1 in conditions such as sepsis. Like Cowley et al. [16], Vargas Hein et al. [2] demonstrated that elevated sELAM-1 levels were corresponding with unfavourable outcomes of severe sepsis. sICAM-1 levels were not significantly different between survivors and non-survivors.

Carlson et al. showed in an in vitro experiment a reduced $\mathrm{T}$-cell binding to activated endothelial cells after catecholamine application, this decrease however did not seem to be mediated by a change in adhesion

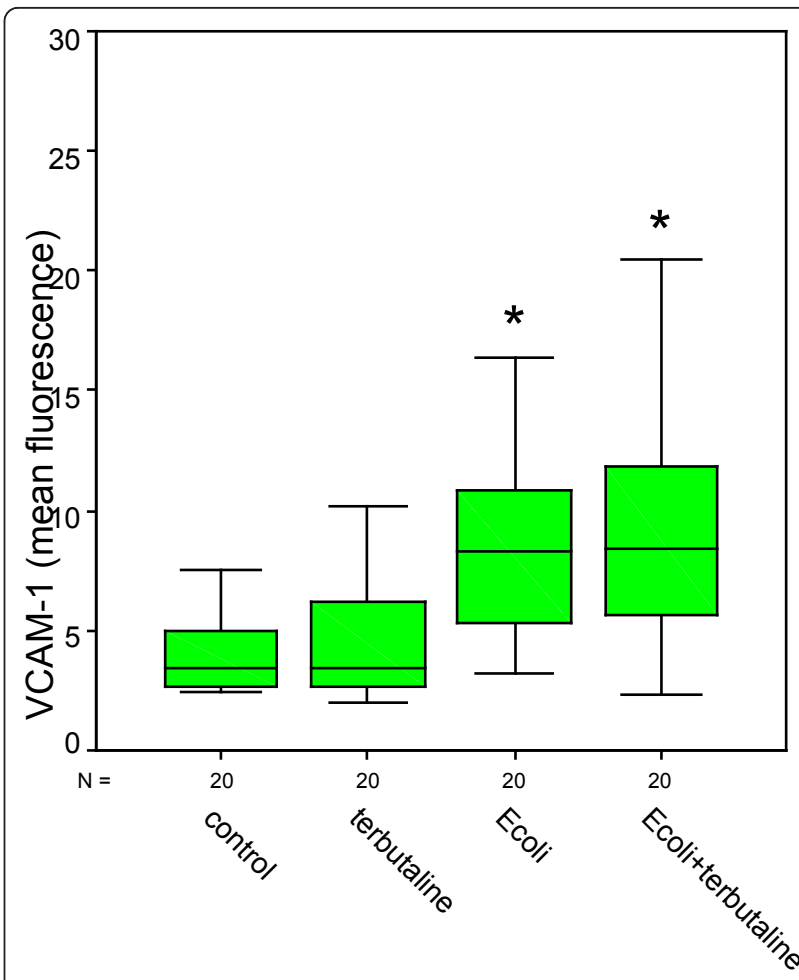

Figure 4 Quantitative changes in CD 106 (VCAM-1) expression following terbutaline $(\boldsymbol{\beta} 2)$ and bacterial (E.coli) stimulation.

${ }^{*}$ statistical analysis $p \leq 0.001$, versus negative control and versus $\beta 2$ stimulation, Wilcoxon test. (The box represents the mid $50 \%$ range of the data. Whiskers are the lines that extend outwards from the ends of the box to a distance of at most 1.5 units of interquartile range.)

molecule expression on either leukocytes or endothelial cells [17]. These effects may at least partly be mediated by a $\beta 1$ and $\beta 2$ induced increase of intracellular cAMP levels. Changes in transcription rates as a result of an increase of intracellular cAMP have been described for a variety of cells [18]. Investigation in the specific effects of increased cAMP levels on endothelial adhesion molecule expression did not lead to clear results. While Pober et al. found a reduced adhesion molecule expression after increasing cAMP levels in TNF $\alpha$ activated endothelial cells [19], other groups did not find effects of changes in cAMP concentrations on adhesion molecule expression $[20,10]$. Regarding the transcription level of adhesion molecules, expression is related to an increased activation of the transcription factor NF- $\kappa$ B [21]. Bacterial heat shock proteins also lead to an increased expression of cytokine and adhesion molecule expression in monocytes and endothelial cells [22].

As the interaction between adrenoceptor stimulation and adhesion molecule expression on stimulated endothelial cells has not been entirely clarified, our group investigated if $\beta$-adrenoceptor agonist administration 
caused an effect on expression of endothelial intercellular adhesion molecules (ICAM-1) and vascular adhesion molecules (VCAM-1) in human umbilical cord endothelial cells (HUVEC). Bacterial activation with $E$. coli itself caused significant increases in the expression of both adhesion molecules. Whereas $\beta 1$ adrenoceptor stimulation with norepinephrine did not cause further increases, $\beta 2$ stimulation with terbutaline led to a further increase in both ICAM-1 and VCAM-1 expressions.

Other groups have investigated different cell types such as pulmonary microvasculature cells [23] or different stimulation mechanisms and found evidence for migration of polymorphonuclear neutrophils mediated by endothelial adhesion molecules. Our method represents an isolated in vitro assay. Factors like underlying and concomitant diseases and their treatment are influencing adhesion molecule formation and release. We were interested if effects of other agents which are frequently used could be observed and lead to changed opinions and therapeutic consequences. In preliminary experiments we determined the optimal concentrations of stimulation and adrenoceptor treatment. Starting with either adrenoceptor or bacterial stimulation did not reveal different results.

We found an effect of bacterial stimulation on ICAM-1 and VCAM-1 adhesion molecule expression which was not markedly influenced neither by administration of the $\beta 1$-adrenergic agent norepinephrine nor the $\beta 2$-adrenergic agent terbutaline. In summary, adrenoceptor stimulation did not lead to further alterations. We have not examined soluble adhesion molecules which may represent a higher proportion of formerly expressed and then detached cells released into the assay or into the bloodstream as shown by other groups [6-8].

\section{Conclusions}

Endothelial adhesion molecules ICAM-1 and VCAM-1 were increased following bacterial stimulation. Administration of adrenoceptor-stimulating substances did not lead to significant increases in stimulated or non-stimulated cells.

In forthcoming studies, the influence of adrenoceptor agonists on endothelial adhesion molecule release will be further investigated.

\section{Acknowledgements}

The study was conducted in cooperation with the Dept. of Obstetrics and Gynaecology of Hannover Medical School.

\section{Author details}

'Dept. of Anaesthesiology \& Intensive Care Medicine, Hannover Medical School Hannover, Germany. ${ }^{2}$ Department of Trauma Surgery, Hannover Medical School Hannover, Germany.

\section{Authors' contributions}

HR has participated in the experimental parts of the study, and written the manuscript, BJ was involved in statistical analysis, MvG and BH have established the technique of HUVEC preparation and developed the experiments. WL and SW carried out and described the experiments. MP and DS have contributed to the manuscript. All authors have read and approved the manuscript.

\section{Competing interests}

H. R. received a grant from the local HiLF-Programme of Hannover Medical School for junior researchers which did not interfere with any possibly competing interests. The author(s) declare that they have no competing interests.

Received: 26 November 2010 Accepted: 25 February 2011

Published: 25 February 2011

\section{References}

1. Lum H, Malik AB: Mechanisms of increased endothelial permeability. Can J Physiol Pharmacol 1996, 74:787-800.

2. Vargas-Hein O, Misterek K, Tessmann JP, van Dossow V, Krimphove M, Spies C: Time course of endothelial damage in septic shock: prediction of outcome. Crit Care 2005, 9:R 323-30.

3. Benschop RJ, Nijkamp FP, Ballieux RE, Heijnen CJ: The effects of badrenoceptor stimulation on adhesion of human natural killer cells to cultured endothelium. Br J Pharmacol 1994, 113:1311-1316.

4. Ferro $A$, Queen LR, Priest RM, Xu B, Ritter JM, Poston L, Ward JP: Activation of nitric oxide synthase by beta 2-addrenoceptors in human umbilical cord vein endothelium in vitro. Br J Pharmacol 1999, 126(8):1872-80.

5. Bateman RM, Walley KR: Microvascular resuscitation as a therapeutic goal in severe sepsis. Crit Care 2005, 9(suppl 4):S 27-32.

6. Leone M, Boutière B, Camoin-Jau L, Albanèse J, Horschowsky N, Mège JL, Martin C, Dignat-George F: Systemic endothelial activation is greater in septic than in traumatic-hemorrhagic shock but does not correlate with endothelial ectivation in skin biopsies. Crit Care Med 2002, 30:808-14.

7. Whalen M, Doughty LA, Carlos T, Wisniewski SR, Kochanek PM, Carcillo JA: Intercellular adhesion molecule -1 and vascular cell adhesion molecule-1 are increased in the plasma of children with sepsis-indurced multiple organ failure. Crit-Care Med 2000, 28:2600-7.

8. Leone $M$, Boutière-Albanèse $B$, Valette $S$, Camoin-Jau L, Barrau K, Albanèse J, Martin C, Dignat-George F: Cell adhesion molecules as a marker reflecting the reduction of endothelial activation induced by glucocorticoids. Shock 2004, 21(4):311-14.

9. Gornikiewicz A, Sautner T, Brostjan C, Schmierer B, Függer R, Roth E, Mühlbacher F, Bergmann M: Catecholamines up-regulate lipopolysaccharide-induced IL-6 production in human microvascular endothelial cells. FASEB J 2000, 14:1093-1100.

10. Morandini R, Ghanem G, Portier-Lemarié A, Robaye B, Renaud A, Boeynaems JM: Action of CAMP on expression and release of adhesion molecules in human endothelial cells. Am J Physiol 1995, 270(Heart Circ Physiol 39):H 807-816.

11. Law MM, Cryer HG, Abraham E: Elevated levels of soluble ICAM-1 correlate with the development of multiple organ failure in severly injured trauma patients. J Trauma 1994, 37:100-110.

12. Sessler CN, Windsor AC, Schartz M, Watson L, Fisher BJ, Sugerman HJ, Fowler AA III: Circulating ICAM-1 is increased in septic shock. Am J Respir Crit Care Med 1995, 151:1420-1427.

13. Xu H, Gonzalo JA, St Pierre Y, Williams IR, Cooper TS, Cotran RS, Springer TA, Gutierrez-Ramos JC: Leukocytosis and resistance to septic shock in intercellular adhesion molecule 1-deficient mice. J Exp Med 1994, 180:95-109.

14. van Griensven M, Probst C, Müller K, Hoevel P, Krettek C, Pape HC: Leukocyte-endothelial interactions via ICAM-1 are detrimental in polymicrobial sepsis. Shock 2006, 25:254-259.

15. Hildebrand F, Pape HC, Harwood P, Müller K, Hoevel P, Pütz C, Siemann A, Krettek C, van Griensven M: Role of adhesion molecule ICAM in the pathogenesis of polymicrobial sepsis. Exp Toxicol Pathol 2005, 56:281-290.

16. Cowley HC, Heney D, Gearing AJH, Hemingway I, Webster NR: Increased circulating adhesion molecule concentrations in patients with the systemic inflammatory response syndrome: A prospective cohort study. Crit Care Med 1994, 22:651-657. 
17. Carlson SL, Beiting DJ, Kiani CA, Abell KM, McGillis JP: Catecholamines decrease lymphocyte adhesion to cytokine-activated endothelial cells. Brain Behav Immun 1996, 10:55-67.

18. Dedendorfer $U$, Oetgen $P$, Libermann TA: Multiple regulatory elements in the Interleukin- 6 gene mediate induction by prostaglandins, cyclic AMP, and lipopolysaccharid. Mol Cell Biol 1994, 14:4443-4445.

19. Pober JS, Slowik MR, De Luca LG, Ritchie AJ: Elevated cyclic AMP inhibits endothelial cell synthesis and expression of TNF-induced endothelial leukocyte adhesion molecule-1, and vascular cell adhesion molecule-1, but not intercellular adhesion molecule-1. J Immunol 1993, 150(11):5114-5123.

20. Delsher TA, Garcia I, Harlan JM: Cytokine-induced adhesion molecule expression on human umbilical vein endothelial cells is not regulated by cyclic adenosine monophosphate accumulation. Life Sciences 1993, 53:365-370.

21. Baeuerle PA, Baichwal VR: NF-kB as a frequent target for immunosuppressive and anti-inflammatory molecules. Adv Immunol 1997, 65:111-137.

22. Galdiero M, Cipollaro de l'Ero G, Marcatili A: Cytokine and Adhesion Molecule Expression in Human Monocytes and Endothelial Cells Stimulated with Bacterial Heat Shock Proteins. Infect Immun 1996, 65(2):699-707.

23. Moreland J, Bailey G, Nauseef WM, Weiss JP: Organism-Specific NeutrophilEndothelial Cell Interactions in Response to Escherichia coli,

Streptococcus pneumoniae, and Staphylococcus aureus. J Immunol 2004, 172:426-432.

doi:10.1186/1756-0500-4-40

Cite this article as: Ruschulte et al: Adrenoceptor stimulation does not affect ICAM-1 and VCAM-1 expression in vitro. BMC Research Notes 2011 4:40.

\section{Submit your next manuscript to BioMed Central and take full advantage of:}

- Convenient online submission

- Thorough peer review

- No space constraints or color figure charges

- Immediate publication on acceptance

- Inclusion in PubMed, CAS, Scopus and Google Scholar

- Research which is freely available for redistribution

Submit your manuscript at www.biomedcentral.com/submit 